\title{
Civilian and military doctors' knowledge of tranexamic acid (TXA) use in major trauma: a comparison study
}

\author{
Jonathan Blair Thomas Herron, ${ }^{1}$ R French, ${ }^{2}$ A D Gilliam ${ }^{2}$
}

${ }^{1}$ Intensive Care, Defence Medical Group (DMG) North, Middlesbrough, UK ${ }^{2}$ General Surgery, County Durham and Darlington NHS Foundation Trust, Darlington, UK

\section{Correspondence to}

Jonathan Blair Thomas Herron, Intensive Care, MDHU North, Middlesbrough TS4 3BW, UK; herronjonny@hotmail.com

Received 14 July 2017 Revised 20 September 2017 Accepted 22 September 2017 Published Online First 9 October 2017
Check for updates

To cite: Herron JBT, French $R$, Gilliam AD.

J R Army Med Corps 2018;164:170-171.

\begin{abstract}
Introduction Tranexamic acid (TXA) administration within the recommended time of 3 hours has been demonstrated to improve outcomes following trauma. The aim of this study was to identify potential knowledge gaps in the administration of TXA in order to target further educational training in those doctors responsible for the management of acute trauma.

Methods 104 military and 852 civilian doctors were invited to complete a four-item web-based questionnaire pertaining to the indications, dose, side effects and evidence base for TXA administration in trauma. Doctors of all grades and surgical specialties including emergency trainees and anaesthetics were surveyed.
\end{abstract}

Results 65 military and 460 civilian doctors responded with a response rate of $62 \%$ and $54 \%$, respectively. Responses were required for every question to allow progression and submission. $93 \%$ of military doctors knew the initial dose of TXA compared with $34 \%$ of civilian doctors. The Clinical randomisation of an Antifibrinolytic in Significant Haemorrhage (CRASH) 2 trial was known to $91 \%$ of military doctors compared with $24 \%$ of civilian doctors. The optimal time for delivery of TXA in under 3 hours was correctly identified by $91 \%$ of military doctors compared with $10 \%$ by civilian doctors.

Discussion Military doctors are more familiar with TXA and its side effect profile. Given the potential impact of TXA on patient outcome and the findings of this study, further education of all doctors is recommended including dose, timing and potential side effects.

\section{INTRODUCTION}

Trauma is one of the leading causes of mortality in the teenage and young adult population. ${ }^{1}$ Worldwide, there are around 480000 deaths annually attributable to major haemorrhage. ${ }^{2}$ Clotting is the mainstay of the body's defence to any compromise to the vascular system resulting in a haemostatic response. ${ }^{3}$ Major trauma can lead to propagation of the 'lethal triad' of hypothermia, acidosis and coagulopathy. ${ }^{4}$ It is known that in trauma, fibrinolysis occurs and antifibrinolytic agents have been shown to reduce blood loss in major haemorrhage. ${ }^{5}$ Since the Clinical randomisation of an Antifibrinolytic in Significant Haemorrhage (CRASH) 2 trial, tranexamic acid (TXA) has become a mainstay in trauma and its use has been investigated in many other settings. ${ }^{2}$ 6-8 Prompt TXA administration within 3 hours improves outcomes by facilitating damage control resuscitation and surgery. ${ }^{9}$ There is also evidence to suggest a reduction in mortality

\section{Key messages}

Military medical officers' knowledge of tranexamic acid (TXA) and its complications in comparison to their civilian colleagues is superior.

- The dose of TXA is $1 \mathrm{~g}$ given within 3 hours.

- Seizures, anaphylaxis, venous thromboembolisms and severe renal impairment are the complications of TXA administration that must be considered.

- Tranexamic acid (TXA) administration within the recommended time of 3 hours has been demonstrated to improve outcomes following trauma.

- Further education of all doctors is recommended including dose, timing and potential side effects.

- This can serve as a platform to allow for the development of training for both military medical officers and their civilian counterparts and identifies a gap in training/knowledge. It is particularly important to contingency operations where military doctors will have to administer TXA at a more junior level and early in the evacuation chain. Military doctors should share their knowledge with civilian colleagues.

by up to $6.5 \%$, and an increase in postoperative haemoglobin in trauma patients with major haemorrhage. ${ }^{910}$ Similarly, there is increasing evidence that TXA can be used in major elective procedures. ${ }^{11-14}$

The aim of this study was to explore the TXA knowledge of civilian and military doctors in the use of TXA.

\section{METHODS}

One hundred and four military and 852 civilian doctors were invited to complete a four-item web-based questionnaire pertaining to the indications, dose, side effects and evidence base for TXA administration in trauma. The survey was sent in equal proportions to three groups which included Consultants, Registrars and Foundation Year (FY)1Core Trainee (CT)2 (Juniors). The first military group were elements from Defence Medical Group North, elements of 16 Close Support Medical Regiment including the reserve squadron, 144 Parachute Medical squadron and Doctors from the 'Northern Deanery'. Participants were asked to complete the survey alone and any time over $2 \mathrm{~min}$ were 
excluded to prevent the potential bias of respondents searching educational resources for the correct answers. Participants were asked to identify themselves as either military or civilian, but otherwise, anonymity was maintained.

Participation in the survey implied consent and the proforma was derived from expected knowledge for prescription of the drug. The survey consisted of four questions: (1) What was the name of the study that demonstrated the efficacy of TXA in major trauma? (2) From memory, what is the dose of TXA in major trauma? (3) What is the optimum time to administer TXA and, finally, (4) What are the potential side effects of TXA administration? The survey questions were chosen based on the practical implications and drug safety profile which a prescriber is expected to be aware of to administer a drug. The CRASH 2trial was also included in the study as this is the most cited and landmark paper regarding TXA administration and the strongest level of evidence for the drug use. All responses were anonymous and the project was an audit of current clinical practice and thus exempted from ethical review.

\section{RESULTS}

Responses were received from 65 military and 460 civilian doctors, with a response rate of $62 \%$ and $54 \%$, respectively. Ninety-three per cent of military doctors $(n=61)$ knew the initial dose of TXA compared with $34 \%(n=287)$ of civilian doctors. There was an awareness of the CRASH 2 trial in 91\% $(n=59)$ of military respondents, and $24 \%(n=202)$ of civilian doctors.

Ninety-one per cent of military doctors $(n=59)$ knew the correct time of administration of less than 3 hours compared with $10 \%(n=84)$ of civilian doctors. Venous thromboembolism was the most frequently recognised side effect by both military $(71 \%, \mathrm{n}=57)$ and civilian doctors $(52 \% \mathrm{n}=445)$. Military doctors recognised renal impairment $(52 \%, \mathrm{n}=34)$ as a complication, compared with only $4 \%$ of civilian doctors $(n=33)$ and similarly, anaphylaxis $(57 \%, \mathrm{n}=37 \%$ and $1 \%, \mathrm{n}=8)$.

Civilian doctors were derived from Emergency medicine $(40 \%)$, Anaesthetics (53\%) and surgery (7\%). No breakdown of specialties was available for the military doctors.

\section{DISCUSSION}

This survey highlights that many doctors' knowledge of TXA administration in a major trauma setting is limited. This is important due to TXA being established as a mainstay of trauma treatment. Military doctors are more familiar with the drug and its side effect profile, which may be due to differences in training and exposure. This is as expected given the frequency of use among clinicians in the military who have served on operational duty. Given the impact of TXA and the findings in this study, it is clear that we would recommend further training in the indications, administration and side effects of TXA given in trauma.
We recognise potential limitations of this study, including that the sample consisted of doctors from one area in England and, second, the response rate for the study was lower from civilian doctors which potentially limits extrapolation of the findings. There is a need for these findings to be repeated in a larger study across a much broader geographical area to examine whether knowledge of TXA is being disseminated and to ascertain if these findings are comparable to other training regions.

Contributors JBTH was the main author but all authors contributed to data collection, design of the paper, analysis and write-up and revision.

Competing interests None declared.

Provenance and peer review Not commissioned; externally peer reviewed.

Data sharing statement The data is completely anonomysed and is available upon request to any persons approved by the MOD to view such data.

(C) Article author(s) (or their employer(s) unless otherwise stated in the text of the article) 2018. All rights reserved. No commercial use is permitted unless otherwise expressly granted.

\section{REFERENCES}

1 GBD 2013 Mortality and Causes of Death Collaborators. Global, regional, and national age-sex specific all-cause and cause-specific mortality for 240 causes of death, 1990-2013: a systematic analysis for the Global Burden of Disease Study 2013. Lancet 2015;385:117-71.

2 Roberts I, Shakur H, Afolabi A, et al. The importance of early treatment with tranexamic acid in bleeding trauma patients: an exploratory analysis of the CRASH-2 randomised controlled trial. Lancet 2011;377:1096-101.

3 Desborough JP. The stress response to trauma and surgery. Br J Anaesth 2000;85:109-17.

4 Mikhail J. The trauma triad of death: hypothermia, acidosis, and coagulopathy. AACN Clin Issues 1999;10:85-94.

5 Perel P, Al-Shahi Salman R, Kawahara T, et al. CRASH-2 (Clinical Randomisation of an Antifibrinolytic in Significant Haemorrhage) intracranial bleeding study: the effect of tranexamic acid in traumatic brain injury--a nested randomised, placebo-controlled trial. Health Technol Assess 2012;16:iii-xii, 1-54.

6 Bruce-Brand R, Dragomir R, Baker J, et al. Cerebrovascular infarction following bilateral total knee arthroplasty and tranexamic acid administration. Acta Orthop Belg 2013;79:351.

7 Wong J, Abrishami A, El Beheiry $\mathrm{H}$, et al. Topical application of tranexamic acid reduces postoperative blood loss in total knee arthroplasty: a randomized, controlled trial. J Bone Joint Surg Am 2010;92:2503-13.

8 Mikhail J. The trauma triad of death: hypothermia, acidosis, and coagulopathy. $A A C N$ Clin Issues 1999;10:85-94.

9 Cap AP, Baer DG, Orman JA, et al. Tranexamic acid for trauma patients: a critical review of the literature. J Trauma 2011;71:S9-14.

10 Shakur H, Roberts I, Bautista R, et al. Effects of tranexamic acid on death, vascular occlusive events, and blood transfusion in trauma patients with significant haemorrhage (CRASH-2): a randomised, placebo-controlled trial. Lancet 2010;376:23-32

11 Hiippala ST, Strid LJ, Wennerstrand MI, et al. Tranexamic acid radically decreases blood loss and transfusions associated with total knee arthroplasty. Anesth Analg 1997:84:839-44

12 Wong J, Abrishami A, El Beheiry H, et al. Topical application of tranexamic acid reduces postoperative blood loss in total knee arthroplasty: a randomized, controlled trial. J Bone Joint Surg Am 2010;92:2503-13.

13 Seo JG, Moon YW, Park SH, et al. The comparative efficacies of intra-articular and IV tranexamic acid for reducing blood loss during total knee arthroplasty. Knee Surg Sports Traumatol Arthrosc 2013;21:1869-74.

14 Okamoto S, Hijikata-Okunomiya A, Wanaka K, et al. Enzyme-controlling medicines: introduction. Semin Thromb Hemost 1997:23:493-501. 